\title{
CMFT Regimen
}

National Cancer Institute

\section{Source}

National Cancer Institute. CMFT Regimen. NCI Thesaurus. Code C10100.

A chemotherapy regimen consisting of cyclophosphamide, methotrexate, fluorouracil, and tamoxifen that may be used in the treatment of breast cancer. 